\title{
Study of tension in the periodontal ligament using the finite elements method
}

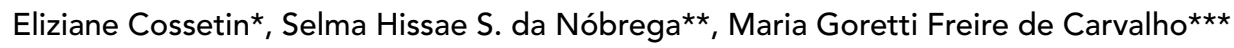

\begin{abstract}
Orthodontic movement is process of transformation of a physical stimulation into a force applied to a tooth, with a biological response identified as bone remodelling. Although it is possible to measure the force applied on a tooth, its distribution around the root is irregular forming areas of higher concentration of tensions, which do not correspond to the force initially applied. To evaluate the behavior of the periodontal ligament after the application of an external action and to prove which would be the areas of higher tension generated in the periodontium, the Finite Elements Method (FEM) was used in comparison to the results obtained in vivo on experimental models in rat. To test the error susceptibility of the technique used in the experimental model, the force application was simulated in three different heights on the mesial surface of the molar. The resulting histological analysis was compared with the result obtained for the computational code and disclosed that the greater focus of osteoclasts in activity had coincided with the compressed areas of the periodontal ligament. The alteration of points of force application generated areas of more extensive deformations in the periodontal ligament, as the point of application was more distant of the initial point, the horizontal force vector became bigger. These results demonstrate that the FEM is an adequate tool to study the distribution of orthodontic forces. The sensitivity of the experimental model used was also observed in relation to the installation of the dental movement device, which should be considered depending on the objective of the research.
\end{abstract}

Keywords: Method of the Finite Elements. Orthodontics. Tensions.

\section{INTRODUCTION}

Dental movement occurs through a transduction process, that is, the transformation of a physical stimulus, which consists of a biologic load applied to the tooth, and the final result is identified by bone remodeling around it.

\footnotetext{
How to cite this article: Cossetin E, Nóbrega SHS, Carvalho MGF. Study of tension in the periodontal ligament using the finite elements method. Dental Press J Orthod. 2012 Jan-Feb;17(1):47.e1-8.
}

The moment the tooth is submitted to mechanical action and the periodontal ligament is forced, some compressed areas are formed and others are tensioned according to the force dissipation around the dental root. On the compressed areas, resorption cells (osteoclasts) activity is

" The author reports no commercial, proprietary, or financial interest in the products or companies described in this article.

* MSc in Dentistry, Specialist in Orthodontics, UNICASTELO.

** PhD in Civil Engineer, USP. Professor, UFRN.

*** PhD in Pathology, UNESP. Professor at Potiguar University. 
observed, whose function is to remove bone, favoring the equilibrium of the periodontal space; and on the tension areas, the action of the osteoblasts occurs in slower speed and start bone neoformation. The force magnitude applied on the dental crown can be easily measured, but the way it is applied must be interpreted by the stress generated all over the periodontal surface. The stress can be interpreted as tension (defined as force per area unit) developed on the adjacent tissues. When a tooth is stimulated, tension distribution over the periodontal area is not equal; there is a higher compression on the cervical and apical areas, and lower tension on the middle third of the root. The magnitude of generated tension, identified here as stress, varies inversely with the area in which the load is applied. ${ }^{12}$

There is some difficulty in clinical studies which relate the load magnitude with the intensity of dental movement, due to three main factors. First, the researchers are unable to control the type of movement, that is, inclination or translation, induced by the devices. Second, as dental movement is non linear and time-dependent, after the activation of the device, the measurement of movement, which is not coordinated by the activation, may systematically influence the results. Third, there are some mistakes concerning measurements, as well as a great variation on the pattern of dental movement both among the patients or the quadrants of an individual patient, being difficult to reach statistically significant data. ${ }^{12}$

Up to now, the technical literature does not provide information about the intensity of force induction or the ideal points for its application, and throughout practice, these parameters are determined exclusively by the experience of orthodontists. Definition about these parameters is very important, because low magnitude load causes deformation of the periodontal ligament and originates cellular activity responsible for bone remodeling. On the other hand, high intensity forces may cause ischemia, cellular death, or in a lower scale, impairs bone resorption, not reaching the aimed results.

According to Toms and Ebrhardt, ${ }^{15}$ the tensions developed in the ligament and alveolar bone provide indications of a favorable or unfavorable tooth movement. Thus, aiming to define parameters for orthodontics practice, researches are performed considering two aspects: the first refers to the experiments comprising humans or animals; and the second refers to the numerical analyses elaborated, based on the Finite Element Method (FEM). Concerning the first aspect, the ethical criteria for in vivo researches are extremely rigorous and the costs for this type of research are high. Besides, sample control represents an additional obstacle, because damage of the orthodontics appliances may occur, patient may miss control appointments, discontinuance of some patients and death of animals. Other additional problems consist in keeping the samples until the end of the experiment, and the sensitivity of the tissues submitted to storing medium, which interfere in its physical properties, requiring accurate evaluation. Regarding the employment of FEM, it has been an excellent computational resource, used for the evaluation of the dental structures concerning several areas of dentistry, $^{7}$ as orthodontics, ${ }^{1,4,10}$ periodontology ${ }^{11}$ and prosthesis. ${ }^{8,9}$ It also represents a cheaper and practical alternative for testing materials and techniques of various specialties cited above.

Jones et $\mathrm{al}^{4}$ tested the physical properties of the periodontal ligament of a tooth under extreme load, through an experiment in humans and by the analysis of a 3D computational model. The results demonstrated the efficacy of the FEM for this purpose. Kawarizadeh et al, ${ }^{5}$ employing the mathematical methodology and the histological interpretation, evaluated the force concentration around the moved teeth of rats and its relationship to the cellular events, concluding that the results were coincident demonstrating 
that FEM can be safely employed for research concerning movement of teeth.

However, it is important to note that the variability on the physical characteristics of the different tissues, added to their interactivity on the response to a stimulus from several origins, constitute a limiting factor for the definition of a more appropriate mathematical model, for analysis via FEM. The mechanical properties of the periodontal ligament are, nowadays, subject of research, for presenting variable conducts according to different animal species, being influenced by the storage methods and experimental research methodologies. ${ }^{6}$

This study comprises researches in the areas of engineering and dentistry aiming to provide to the clinician and the researcher, with an additional way to evaluate planning and biomechanics options, before application on a patient. This research aimed to testify, by numerical experimentation, the results obtained through in vivo experiments and to test the sensitivity of the technique employed for tooth movement, concerning the specific site where the load is applied. From the experiment with rats, the cellular events which occurred from the applied mechanical forces were analyzed and, consequently, compared to the results obtained from FEM, which is being employed in the biomechanical analysis.

\section{MATERIAL AND METHODS}

Analysis of the experimental model

The experiment consisted in identifying, through a histological analysis, the presence of cellular elements which represented compressed and stretched areas of the periodontal ligament, demonstrating the load distribution around the root extension. These areas were obtained from a modified model described by Heller and Nanda, ${ }^{3}$ in which the tooth movement was performed on the first upper left molar of rats, employing a premanufactured nickel-titanium closed coil spring (Morelli-SP, Brazil) $7 \mathrm{~mm}$ long, fixed on that tooth and anchored on the incisor of the same arch, with a load corresponding to $0.25 \mathrm{~N}$. The force was calibrated employing a digital dynamometer and transferred to the mouth with a caliper (Fig 1). The sample consisted of six female Wistar rats, 70 days old, proceeding from Potiguar University, under authorization of the Ethics Committee. All the procedures were performed under general anesthesia. During the experimental period, the animals stayed in appropriate cages, with temperature ranging from 23 to $25^{\circ} \mathrm{C}$, with an inverted light cycle and they were fed with pasty food and water ad libitum. After 7 days, the animals were sacrificed in $\mathrm{CO}_{2}$ chambers and their heads were fixed in 10\% formalin for $48 \mathrm{~h}$. After fixation, the pieces were decalcified with nitric acid at $7.5 \%$,
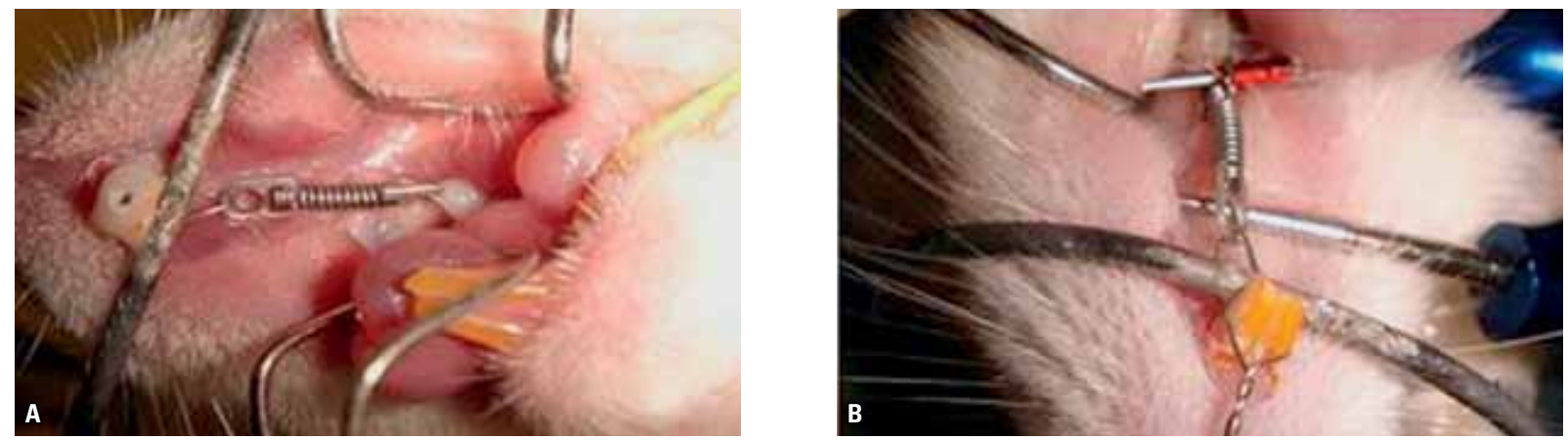

FIGURE 1 - A) Spring system to apply the load on the molar; (B) transferring the load with caliper opening. 
for 5 days, maximum. Afterwards, the left maxillary hemiarches were cleaved; the samples were immersed in paraffin and sectioned $4 \mu \mathrm{m}$ thick, until the root pulp was observed. They were stained with hematoxylin and eosin (HE).

In the histological evaluation, the compression areas could be identified by the presence of resorption cells (osteoclasts), by the absence of any type of cells (hyalinization areas) or by root resorption, which occurs due to excessive compression. Those situations can be seen in Figure 2. The strain areas were related to the absence of osteoclasts.

\section{Analysis by FEM}

\section{Description of the mathematical model}

In order to determine tooth geometry for dental structure analysis employing FEM, the removal of the upper molar of a rat was necessary as well as to photograph it in a stereomicroscope, without the central roots, to facilitate its modeling (Fig 3). The photograph printed on graph paper enabled the establishment of the coordinates of interest.
Nine-nodes quadrilateral finite elements, for the Stress Plan of the computational code ADINA (Automatic Dynamic Incremental Nonlinear Analysis) - version 8.3, comprised the discretization mesh presented in Figure 4. In the same Figure, there are three dental structures: Tooth, bone and periodontal ligament, admitted as homogeneous and isotropic media.

The physical properties were extracted from the research of Kawarizadeh et $\mathrm{al}^{5}$ and are presented in Table 1 .

The elastic bilinear behavior of the ligament is highlighted, which on the initial phase of the movement presents great mobility with elasticity module $\mathrm{E}_{1}$ similar to $0.15 \mathrm{MPa}$ and, when reaching deformation limit of $6.3 \%$, changes to module $\mathrm{E}_{2}$ equal to $0.60 \mathrm{MPa}$ with reduced mobility.

The load of $0.25 \mathrm{~N}$ given by a coil spring had its direction defined from its decomposition towards the mesial and occlusal directions, as illustrated in Figure 5 and towards lingual and mesial directions, as illustrated in Figure 6.
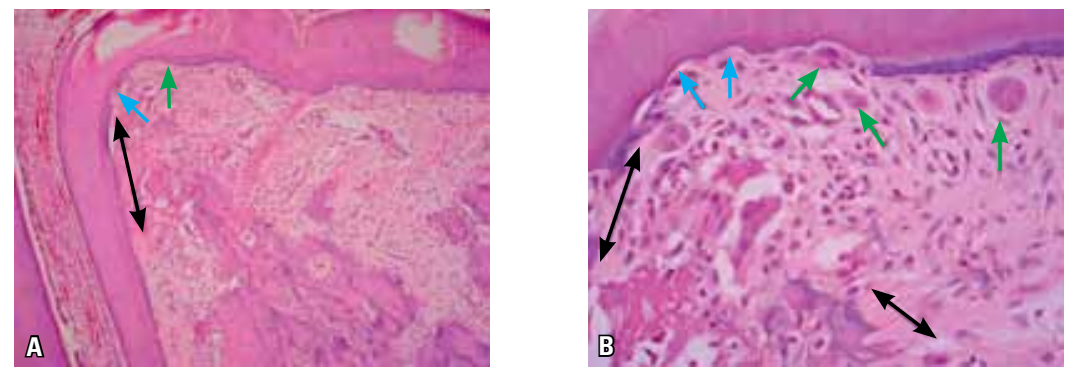

FIGURE 2 - Compression regions in the periodontal ligament: moderate hyalinization (black arrow), osteoclasts (green arrows) and root resorption (blue arrows). HE: A) 100X and B) 400X.

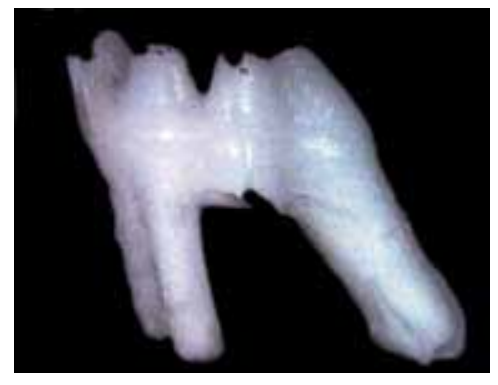

FIGURE 3 - Stereophotography of the upper molar.

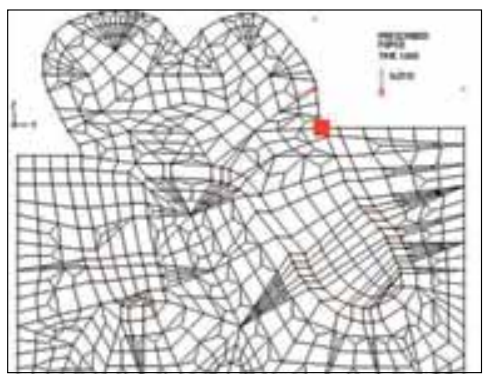

FIGURE 4 - Finite elements mesh. 
TABLE 1 - Physical properties of the tissues.

\begin{tabular}{ccc}
\hline Tissue & $\begin{array}{c}\text { Elasticity } \\
\text { modulus }(\mathrm{Pa})\end{array}$ & $\begin{array}{c}\text { Poisson } \\
\text { coefficient }\end{array}$ \\
\hline $\begin{array}{c}\text { Tooth } \\
\begin{array}{c}\text { Periodontal } \\
\text { ligament }\end{array}\end{array}$ & $\begin{array}{c}\text { Elastic bilinear } \\
\text { Bone.00 }\end{array}$ & 0.30 \\
\hline Bone & $2,000.00$ & 0.45 \\
\hline
\end{tabular}

\section{Alteration of the point of force application}

In order to evaluate the influence of the applied force height and the error susceptibility of the technique employed on the experimental model, related to tooth movement, concerning small deviation on the spring position in relation to the occlusal aspect of the tooth, the force was applied at $0.38 \mathrm{~mm}$ high, from the cervical margin of the tooth (point highlighted in Fig 4), $0.64 \mathrm{~mm}$ and $0.83 \mathrm{~mm}$, keeping the same anchorage for the three situations.

\section{RESULTS}

\section{Experimental model}

As shown in Figure 2, 100\% of the sample presented greater concentration of osteoclasts, root resorption and hyalinization on the furcation area, starting from the center towards distal direction, and along the distal root in its mesial aspect, especially from the middle third of the root to the furcation. According to the proposed interpretation, these areas were considered as regions of higher compression of the periodontal ligament, corresponding to the areas of bone resorption.

\section{Numerical model}

When the load was applied $0.38 \mathrm{~mm}$ from the cervical margin, the numerical simulation employing Finite Elements produced the deformations and effective tensions, presented in Figures 7 and 8 , respectively.

The highlighted area in Figure 7 indicates the compressed region, reference for validation of the

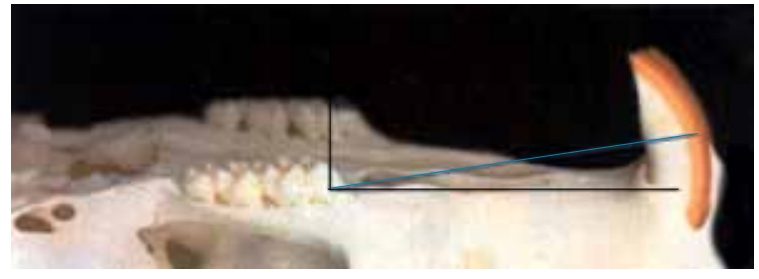

FIGURE 5 - Occlusal and mesial force components.

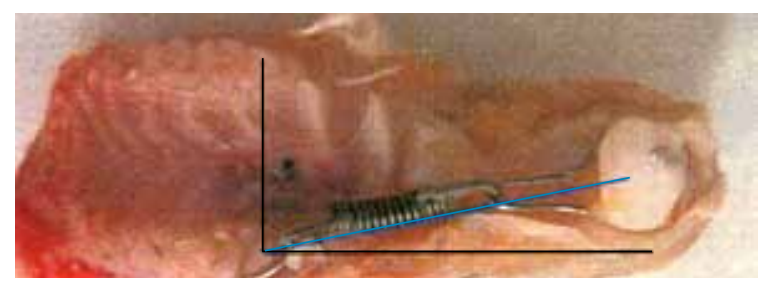

FIGURE 6 - Lingual and mesial force components.

numerical procedure. The maximum horizontal strains obtained from the numerical analysis on the ligament region was $0.03198 \%$, inferior to its strain limit, indicating that the force applied presented low intensity, favoring cellular activity for bone resorption. In Figure 8, it was possible to observe higher stresses around the smaller root and the occurrence of maximum stress in the alveolar bone, originating regions of bone neoformation.

The distribution of deformations obtained from heights at $0.64 \mathrm{~mm}$ and $0.83 \mathrm{~mm}$ from the cervical margin demonstrated to be similar between them and to the previous (Figs 9 and 10), differing on the propagation of areas, which were amplified. The deformations, as well as the effective tensions, increased in intensity with the greater of point of force application height. Table 2 presents the maximum values obtained from the analyses.

The effective stresses values on the periodontal ligament indicate that the experiment produced results on the elastic linear regimen in which the tension limit is equivalent to $9450 \mathrm{~N} / \mathrm{m}^{2}$. 


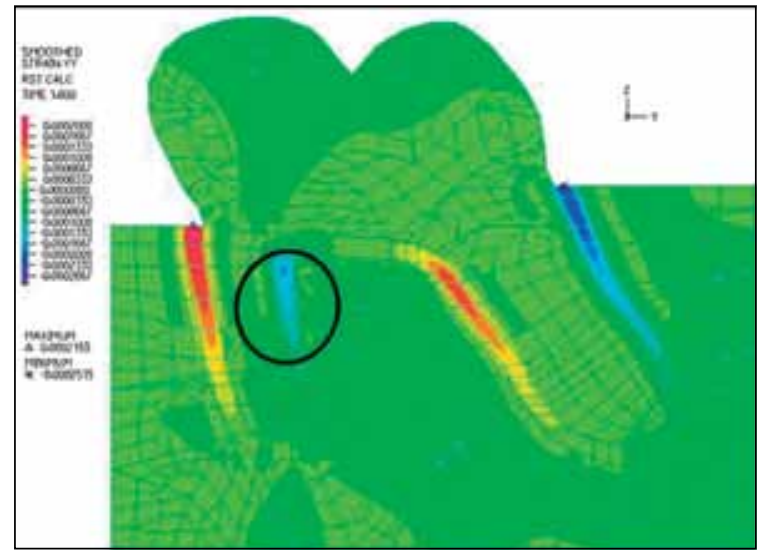

FIGURE 7 - Strains due to load application at $0.38 \mathrm{~mm}$ from the cervical margin.

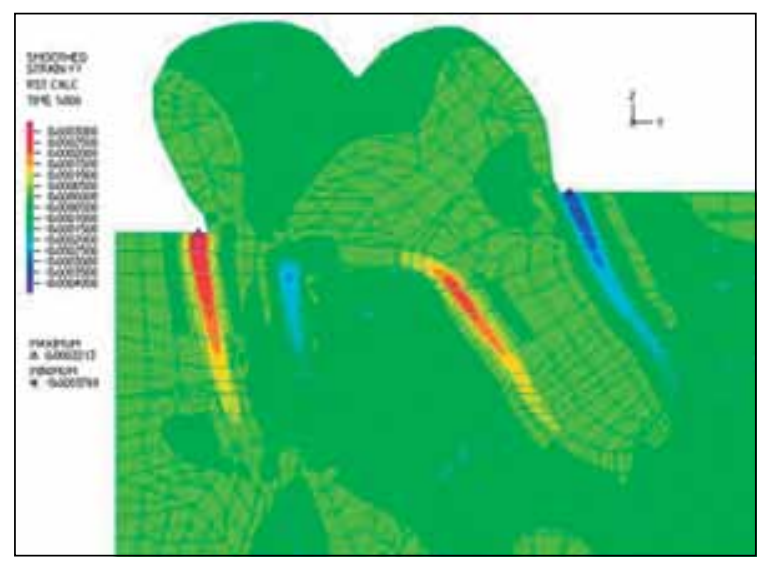

FIGURE 9 - Horizontal strain for load at $0.64 \mathrm{~mm}$ from the cervical margin.

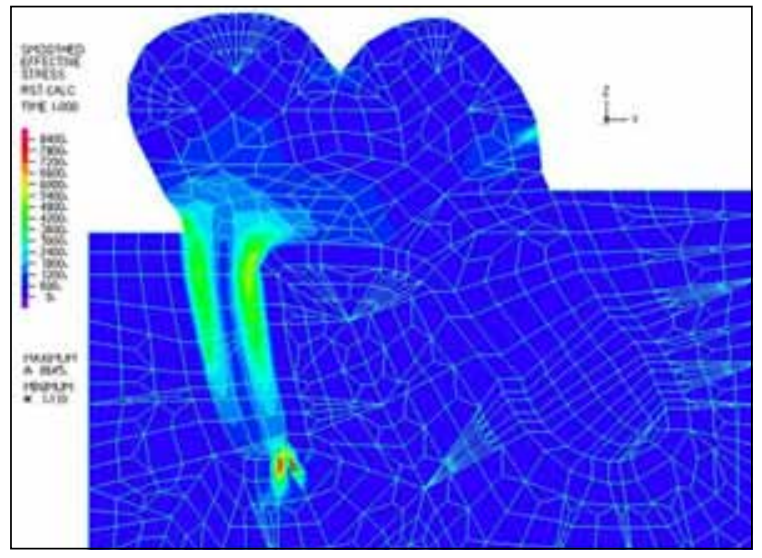

FIGURE 8 - Effective stress due to force application at $0.38 \mathrm{~mm}$ from the cervical margin.

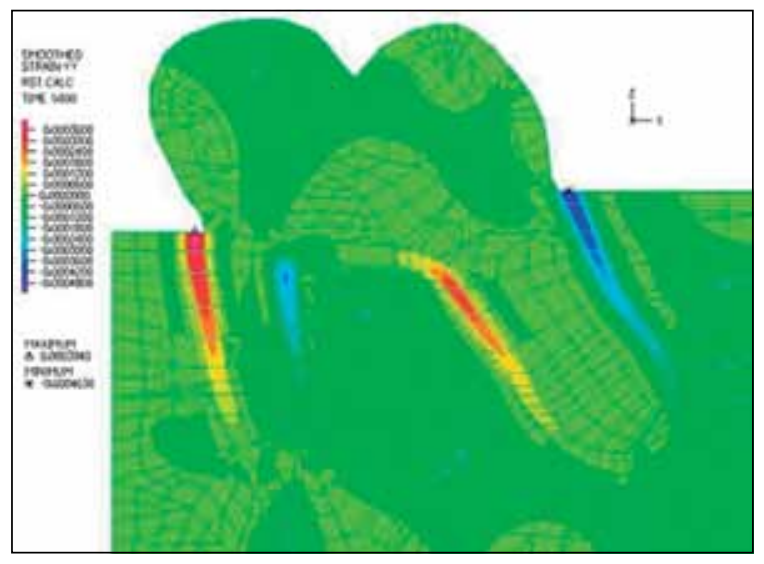

FIGURE 10 - Horizontal strain for load at $0.83 \mathrm{~mm}$ from the cervical margin.

TABLE 2 - Stresses and strains for load applied at $0.38 \mathrm{~mm}, 0.64 \mathrm{~mm}$ and $0.83 \mathrm{~mm}$.

\begin{tabular}{ccccc} 
& & $0.38 \mathrm{~mm}$ & $0.64 \mathrm{~mm}$ & $0.83 \mathrm{~mm}$ \\
Periodontal ligament & Strains $(\%)$ & 0.0319821 & 0.0481154 & 0.0597829 \\
\cline { 2 - 4 } Bone & Effective stresses $\left(\mathrm{N} / \mathrm{m}^{2}\right)$ & $7.04292 \times 10^{+1}$ & $1.09042 \times 10^{+2}$ & $1.35718 \times 10^{+2}$ \\
& Effective stresses $\left(\mathrm{N} / \mathrm{m}^{2}\right)$ & $1.32567 \times 10^{+4}$ & $2.03861 \times 10^{+4}$
\end{tabular}

\section{DISCUSSION}

The presented results aim to confirm the efficiency of employing FEM for qualitative evaluation of dental movement. For this reason, the two dimension model for the Stress Plan and the bilinear elastic behavior of the periodontal ligament were chosen. It is important to highlight that the mechanical behavior of the ligament, due to its variability among samples, is a topic for research nowadays. Models which consider the linearity or non-linearity, viscous elastic behavior, anisotropism of the medium, have been presented, but the results have generated some controversy. ${ }^{6}$

The elastic model used for the ligament, produced the results showed in Figure 7, which in confrontation to Figure 2A, demonstrated that FEM 
provides results in accordance to the ones truly obtained. This fact indicates the possibility of adjusting load levels to be applied to the teeth and the resulting movements, avoiding high intensity load and its resultant problems.

In relation to the study concerning force application height, it can be observed in Table 2 that the described values are progressively higher with the elevation of the point of force application, identified in Figure 4. This fact happened because the direction of the inclined force was altered for each situation of analysis, placing it more horizontal as the height of force application was more distant from the cervical margin, maintaining the anchorage point on the incisors. The anchorage was defined on the mathematical model as the origin of the force vector, indicated in Figure 6. It is evident that during the experiment the real direction could not be established, due to the difficulty in making the measurements, but as the aim of this work consisted on the qualitative evaluation of the heightening of the point of force application, it was considered pertinent, for the numerical analysis, to keep as reference the origin of the force vector. Thus, the magnitude of the horizontal force projection, responsible for a more significant movement of the tooth, was higher in each analysis, producing, consequently, small expansions on the stressed and strained areas.

Among the necessary studies to confirm the adequacy of FEM for quantitative analyses, additional researches on the mechanical behavior of the periodontal ligament are mandatory. In such case, tridimensional analyses will need to be done aiming to consider all the parameters involved in tooth movement.

For the orthodontists, there is a new option for planning and research, employing a tool which allows a previous simulation of force mechanisms versus dental movement.

\section{CONCLUSIONS}

The results obtained show a satisfactory correlation between experimental and numerical data, justifying the efficiency of the Finite Element Method to analyze problems related to tooth movement, especially when studying orthodontic force distribution.

Small variation towards force application height, mathematically tested, demonstrated the existence of sensitivity of the technique employed on the experimental model, in relation to the installation of the device for tooth movement. Depending on the objective of the research, theses variations should be taken into consideration. 


\section{REFERENCES}

1. Cattaneo PM, Dalstra M, Melsen B. The finite element method: a tool to study orthodontic tooth movement. J Dent Res. 2005;84(5):428-33.

2. Consolaro A. Reabsorções dentárias nas especialidades clínicas. $2^{a}$ ed. Maringá: Dental Press; 2005.

3. Heller IJ, Nanda R. Effect of metabolic alteration of periodontal fibers on orthodontic tooth movement. Am J Orthod. 1979;75(3):239-58.

4. Jones ML, Hickman J, Middleton J, Knox J, Volp C. A validated finite element method study of orthodontic tooth movement in the human subject. J Orthod. 2001;28(1):29-38.

5. Kawarizadeh A, Bourauel C, Zhang D, Götz W, Jäger A. Correlation of stress and strain profiles and the distribution of osteoclastic cells induced by orthodontic loading in rat. Eur J Oral Sci. 2004 Apr;112(2):140-7.

6. Kawarizadeh A, Bourauel C, Jäger A. Experimental and numerical determination of initial tooth mobility and material properties of the periodontal ligament in rat molar specimens. Eur J Orthod. 2003;25(6):569-78.

7. Lotti RS, Machado AW, Mazzieiro ET, Landre Júnior J, Aplicabilidade científica do método dos elementos finitos. Rev Dental Press Ortod Ortop Facial. 2006;11(2):35-43.

8. Mori M, Ueti M, Matson E, Saito T. Estudo da distribuição das tensões internas, sob carga axial, em dente hígido e em dente restaurado com coroa metalocerâmica e retentor intra-radicular fundido - método do elemento finito. Rev Odontol Univ São Paulo. 1997;11(2):99-107.
9. Gomes de Oliveira S, Seraidarian PI, Landre J Jr, Oliveira DD, Cavalcanti BN. Tooth displacement due to occlusal contacts: a three-dimensional finite element study. J Oral Rehabil. 2006;33(12):874-80.

10. Oyama K, Motoyoshi M, Hirabayashi M, Hosoi K, Shimizu N Effects of root morphology on stress distribution at the root apex. Eur J Orthod. 2007;29(2):113-7.

11. Petrie CS, Williams JL. Probabilistic analysis of peri-implant strain predictions as influenced by uncertainties in bone properties and occlusal forces. Clin Oral Implants Res. 2007 Oct;18(5):611-9.

12. Quinn RS, Yoshikawa DK. A reassessment of force magnitude in orthodontics. Am J Orthod. 1985;88(3):252-60.

13. Schwarz AM. Tissue changes incident to orthodontic tooth movement. Int J Orthod. 1932;18:331-52

14. Storey E. The nature of tooth movement. Am J Orthod. 1973;63(3):292-315

15. Toms SR, Eberhardt AW. A nonlinear finite element analysis of the periodontal ligament under orthodontic tooth loading. Am J Orthod Dentofacial Orthop. 2003;123(6):657-65

16. Waldo CM, Rothblatt JM. Histologic response to tooth movement in the laboratory rat. J Dent Res. 1954;33(4):481-6.

\section{Contact address}

